\title{
The regulatory role of immunosuppressants on immune abnormalities in acute pancreatitis
}

\author{
LIGENG DUAN $^{1}, \mathrm{YU} \mathrm{MA}^{1}, \mathrm{JUNLIN} \mathrm{CHI}^{1}, \mathrm{XU} \mathrm{WANG}^{2}, \mathrm{ALEXANDER} \mathrm{J.} \mathrm{WESLEY}^{3}$ and XIAOLI CHEN ${ }^{1}$ \\ Departments of ${ }^{1}$ General Surgery and ${ }^{2}$ Nursing, West China Hospital, West China Medical School, \\ University of Sichuan, Chengdu, Sichuan 610041, P.R. China; ${ }^{3}$ Department of Surgery, \\ Division of Transplantation, University of Cincinnati Medical Center, Cincinnati, OH 45221-0091, USA
}

Received September 06, 2013; Accepted October 04, 2013

DOI: $10.3892 /$ br.2013.208

\begin{abstract}
The uncontrolled progression of the inflammatory cascade is the main cause underlying the development of multiple organ dysfunction syndrome (MODS) in acute pancreatitis. In this study, we investigated the effects of several immunosuppressants on mitigating the systemic inflammatory reaction syndrome (SIRS) and the compensatory anti-inflammatory response syndrome (CARS) associated with acute pancreatitis. A total of 93 male Sprague Dawley rats were divided into 5 groups: group 1 was the sham group and group 2 underwent laparoscopic intrapancreatic duct injection of sodium taurocholate to induce pancreatitis. The remaining 3 groups were the same as group 2, with the addition of methylprednisolone, cyclophosphamide or methotrexate treatment (metastab, CTX or MTX groups, respectively). Following establishment of the acute pancreatitis model, the serum levels of inflammatory and anti-inflammatory cytokines in groups 2 , 3, 4 and 5 were found to be significantly elevated. Following immunosuppressant administration, the levels of all inflammatory and anti-inflammatory cytokines investigated in groups 3 , 4 and 5 were decreased compared to those in group 2. The pancreatic amylase levels and pancreatic wet weight (PWW) were also decreased in groups 3,4 and 5 compared to those in group 2. Therefore, immunosuppressants may reduce inflammation-related cytokine levels in acute pancreatitis and relieve disease progression.
\end{abstract}

\section{Introduction}

Following wide acceptance of the concept of systemic inflammatory reaction syndrome (SIRS), the association between acute pancreatitis and SIRS was extensively investigated $(1,2)$.

Correspondence to: Dr Xiaoli Chen, Department of General Surgery, West China Hospital, Medical Center, University of Sichuan, Chengdu, Sichuan 610041, P.R. China

E-mail: oxbb512@126.com

Key words: acute pancreatitis, systemic inflammatory reaction syndrome, cytokine, methylprednisolone, cyclophosphamide, methotrexate
SIRS associated with acute pancreatitis is characterized by fever, fluctuation of vital signs (blood pressure, pulse and respiratory rate) and increased white blood cell count, as well as a cascade of inflammatory cytokine and mediator production that leads to cell proliferation and activation, with extensive systemic inflammatory changes of the small vessel endothelial cells (3-5). The release of copious amounts of inflammatory mediators leads to microcirculatory disturbances and leukocyte-mediated release of arachidonic acid metabolites, oxygen-free radicals, nitrogen-oxygen compounds and proteases. These secondary inflammatory mediators may cause organ and cell injury and the whole process may ultimately develop into systemic multiple organ dysfunction syndrome (MODS) (6-8).

The pathological progression of uncontrolled inflammatory response leading to tissue injury is common to several autoimmune diseases, such as inflammatory bowel disease (IBD), rheumatoid arthritis (RA) and systemic lupus erythematosus (SLE), all of which share similar basic pathological changes. As an example, RA and SLE patients exhibit elevated tumor necrosis factor (TNF)- $\alpha$ and interleukin (IL)-1 levels, which are the initiating factors for the inflammatory cytokine cascade (9-12), inflammatory cell infiltration, local blood circulation dysfunction and autoimmune self-destruction (13-16). Pancreatitis and autoimmune disorders use NF- $\kappa \mathrm{B}$ and other pro-inflammatory factors on the surface of inflammatory cells, such as Toll-like receptors, to initiate the inflammatory response $(17,18)$. Treatments for preventing SIRS, such as TNF- $\alpha$ monoclonal antibody (19-22) and activated protein C (APC) $(23,24)$, have been used to treat autoimmune diseases and have achieved some success. Over the years, IBD, RA, SLE and other autoimmune diseases have been efficiently treated using classical immunosuppressants. Therefore, we hypothesized that there is a similar pathogenetic and pathological basis to autoimmune diseases and acute pancreatitis-associated SIRS, which suggests that classical immunosuppressants may be useful in the treatment of pancreatitis. Previous studies on corticosteroids and 5-fluorouracil demonstrated their potential in effectively treating acute pancreatitis (25-28). These classical immunosuppressants have already been used long-term in the clinical setting and they may be safer and more readily available compared to new drugs if proven to be effective in the management of acute pancreatitis. 
The purpose of this study was to observe the effects of commonly used immunosuppressants in acute pancreatitis and to determine their mechanism of immune downregulation for mitigating disease progression.

\section{Materials and methods}

Experimental animals. A total of 93 male Sprague Dawley (SD) rats, 10-12 weeks old and weighting 200-250 g, were provided by the Center of Experimental Animals, University of Sichuan (Chengdu, China). The project was approved by the Medical Ethics Committee of the University of Sichuan.

Reagents. Sodium taurocholate, rH-IL-1, rH-IL-6 and rH-TNF (recombinant human cytokine standards) were purchased from Sigma (St. Louis, MO, USA). The cultured L929 and MH60 cell lines were prepared by the Immune Research Department of the University of Sichuan. RPMI-1640 cell culture medium and fetal bovine serum were purchased from Gibco-BRL (Gaithersburg, MD, USA). ${ }^{3} \mathrm{H}$-marked thymidine was prepared by the Shanghai Institute of Nuclear Research, (Shanghai, China). Methyl thiazol tetrazolium (tetrazolium was freshly prepared after phosphate-buffered saline solution filter sterilization, with preservation in the dark) was purchased from Sigma. Other materials and their suppliers were as follows: actinomycin D, (Sigma); 96-hole flat cell culture plates (Nalge Nunc, Naperville, IL, USA); sIL-2R kit (Norman Bethune Medical University, Changchun, China); $20 \%$ sodium dodecyl sulphate-50\% dimetylformamide solution (Sichuan University); rat transforming growth factor (TGF)- $\beta 1$ enzyme-linked immunosorbent assay (ELISA) commercial reagents kit (crystal-US Beijing Biological Engineering company, Beijing, China; packed and imported by Sigma); commercial ELISA detection reagents kit for rat IL-10 (catalog no. KRC0100-SB, crystal-US Biological Engineering company); methylprednisolone (Pharmacia \& Upjohn, Peapack, NJ, USA); cyclophosphamide and methotrexate acridine (Shanghai Hualian Pharmaceutical Co., Ltd., Shanghai, China).

Animal grouping and model preparation. A total of 93 SD rats were fasted but allowed access to drinking water for $16 \mathrm{~h}$ prior to the experiment. The rats were divided into 5 groups: group 1 was the sham control group $(n=6)$ : the rats received anesthesia and a laparotomy without ductal injection or treatment and were sacrificed $2 \mathrm{~h}$ after the operation. Group 2 was the acute pancreatitis group $(n=24)$ : anesthesia was achieved with intraperitoneal administration of $5 \%$ chloral hydrate and a laparotomy was performed under aseptic conditions. Subsequently, an intra-cholangiopancreatic duct injection with 5\% sodium taurocholate $(1.0 \mathrm{ml} / \mathrm{kg})$ was performed to create a pancreatitis model, without further treatment (29). Pancreatitis was induced in the remaining 3 groups $0.5 \mathrm{~h}$ prior to injection via the dorsal penile vein with the indicated medications: group 3 $(\mathrm{n}=21)$ received $30 \mathrm{mg} / \mathrm{kg}$ methylprednisolone (metastab); group $4(\mathrm{n}=21)$ received $20 \mathrm{mg} / \mathrm{kg}$ cyclophosphamide (CTX); and group $5(\mathrm{n}=21)$ received $1.2 \mathrm{mg} / \mathrm{kg}$ methotrexate (MTX). All the animals received subcutaneous infusion of $6 \mathrm{ml} / \mathrm{kg} / \mathrm{h}$ saline after all the procedures were completed. In groups 2 , 3, 4 and 5, the surviving animals were sacrificed at different time points (6 rats were sacrificed at $2 \mathrm{~h}$, another 6 rats at $6 \mathrm{~h}$ and the remaining at $24 \mathrm{~h}$ ). Prior to the sacrifice, a laparotomy and abdominal aorta puncture were performed to harvest blood samples to measure the plasma levels of TNF- $\alpha$, IL-1, IL6, IL-10, TGF- $\beta$, pancreatic amylase and white blood cell (WBC) and differential counts. The pancreas was excised to determine pancreatic wet weight (PWW).

Assay parameters and methodology. All the cytokines were quantitated by the Department of Immunology Laboratory, West China Medical School, University of Sichuan. The methods of detecting IL-1, IL-6 and TNF- $\alpha$ were in accordance with the standards provided by Lederer (30), Kimura (31) and Heo (32) and the use of bioassay testing (24-26) for Il-10 and TGF- $\beta 1$ was in strict accordance with the methods described in the commercial kit, using an enzyme immunoassay method for detection. The samples were sent to the Clinical Laboratory Center of West China Hospital of the University of Sichuan for testing serum amylase, WBC and differential counts.

Statistical analysis. We used analysis of variance for continuous variables to detect variation among groups at the same time points. All the tests were performed with SAS software, version 9.0 (SAS Institute, Cary, NC, USA). $\mathrm{P}<0.05$ was considered to indicate statistically significant differences. All the reported P-values are two-sided. Continuous variables are described as means \pm standard deviation, unless otherwise stated.

\section{Results}

Animal survival. Four of the 24 animals in group 2 died following establishment of acute pancreatitis, at 4, 6, 8 and $15 \mathrm{~h}$. No animals died in the sham control group or in groups 3 and 4 throughout the trial. One animal in group 5 was found dead $12 \mathrm{~h}$ after the induction of pancreatitis.

Cytokines. In the sham control group, the plasma levels of TNF- $\alpha$, IL-1, IL-6, IL-10 and TGF- $\beta$ were only detected in trace amounts, as a result of tissue injury. In groups 2, 3, 4 and 5 , the plasma levels of the pro-inflammatory cytokines IL-1, IL- 6 and TNF- $\alpha$ increased rapidly and were significantly higher at the 2, 6 and $24 \mathrm{~h}$ time points when compared to those in group 1 at the same time points $(\mathrm{P}<0.05)$ (Table I). Following treatment with immunosuppressants, the plasma levels of TNF- $\alpha$ in groups 3, 4 and 5 at the 6 and $24 \mathrm{~h}$ time points were significantly decreased in comparison to those in group $2(\mathrm{P}<0.05)$. After the treatment, the plasma levels of IL-1 and IL- 6 at the 2, 6 and 24 h time points were significantly decreased in groups 3, 4 and 5, in contrast to those in group 2 $(\mathrm{P}<0.05)$. In our preliminary experiment, we observed that the levels of anti-inflammatory cytokines started to change $24 \mathrm{~h}$ after the induction of acute pancreatitis in the animal model; thus, in this experiment, we measured the plasma concentrations of IL-10 and TGF- $\beta$ using similar methods and timing. It was observed that in group 2, the plasma levels of IL-10 and TGF- $\beta$ in animals with acute pancreatitis were significantly higher $(\mathrm{P}<0.05)$. In the groups treated with immunosuppressants (groups 3, 4 and 5), the plasma levels of IL-10 and TGF- $\beta$ were significantly decreased compared to those in group 2 
Table I. Serum changes in pro-inflammatory cytokine levels.

A, Changes in IL-1 levels

\begin{tabular}{lccccc}
\hline $\begin{array}{l}\text { IL-1 } \\
(\mathrm{IU} / \mathrm{ml})\end{array}$ & $\begin{array}{c}\text { Sham control } \\
\text { group }\end{array}$ & $\begin{array}{c}\text { Pancreatitis } \\
\text { group }\end{array}$ & $\begin{array}{c}\text { Metastab } \\
\text { group }\end{array}$ & $\begin{array}{c}\text { CTX } \\
\text { group }\end{array}$ & $\begin{array}{c}\text { MTX } \\
\text { group }\end{array}$ \\
\hline $2 \mathrm{~h}$ & $0.60 \pm 0.085$ & $1.02 \pm 0.119^{\mathrm{a}}$ & $0.76 \pm 0.095$ & $0.85 \pm 0.176^{\mathrm{b}}$ & $0.82 \pm 0.153$ \\
$6 \mathrm{~h}$ & $0.60 \pm 0.085$ & $1.13 \pm 0.17^{\mathrm{a}}$ & $0.71 \pm 0.102^{\mathrm{b}}$ & $0.75 \pm 0.13^{\mathrm{b}}$ & $0.76 \pm 0.086^{\mathrm{b}}$ \\
$24 \mathrm{~h}$ & $0.56 \pm 0.055$ & $1.15 \pm 0.129^{\mathrm{a}}$ & $0.95 \pm 0.126^{\mathrm{b}}$ & $0.91 \pm 0.171^{\mathrm{b}}$ & $0.85 \pm 0.214^{\mathrm{b}}$ \\
\hline
\end{tabular}

B, Changes in IL-6 levels

\begin{tabular}{lccccc}
\hline $\begin{array}{l}\text { IL-6 } \\
(\mathrm{IU} / \mathrm{ml})\end{array}$ & $\begin{array}{c}\text { Sham control } \\
\text { group }\end{array}$ & $\begin{array}{c}\text { Pancreatitis } \\
\text { group }\end{array}$ & $\begin{array}{c}\text { Metastab } \\
\text { group }\end{array}$ & $\begin{array}{c}\text { CTX } \\
\text { group }\end{array}$ & $\begin{array}{c}\text { MTX } \\
\text { group }\end{array}$ \\
\hline $2 \mathrm{~h}$ & $74.33 \pm 16.26$ & $98.83 \pm 12.43^{\mathrm{a}}$ & $71.0 \pm 8.39^{\mathrm{b}}$ & $72.83 \pm 8.01$ & $85.0 \pm 10.7^{\mathrm{b}}$ \\
$6 \mathrm{~h}$ & $74.33 \pm 16.26$ & $101.0 \pm 15.07^{\mathrm{a}}$ & $70.0 \pm 7.21^{\mathrm{b}}$ & $71.5 \pm 3.39^{\mathrm{b}}$ & $74.83 \pm 21.68^{\mathrm{b}}$ \\
$24 \mathrm{~h}$ & $69.0 \pm 6.40$ & $127.17 \pm 13.91^{\mathrm{a}}$ & $98.83 \pm 11.11^{\mathrm{b}}$ & $105.0 \pm 17.39^{\mathrm{b}}$ & $97.67 \pm 18.88^{\mathrm{b}}$ \\
\hline
\end{tabular}

C, Changes in TNF- $\alpha$ levels

\begin{tabular}{lccccc}
\hline $\begin{array}{l}\text { TNF- } \alpha \\
(\mathrm{IU} / \mathrm{ml})\end{array}$ & $\begin{array}{c}\text { Sham control } \\
\text { group }\end{array}$ & $\begin{array}{c}\text { Pancreatitis } \\
\text { group }\end{array}$ & $\begin{array}{c}\text { Metastab } \\
\text { group }\end{array}$ & $\begin{array}{c}\text { CTX } \\
\text { group }\end{array}$ & $\begin{array}{c}\text { MTX } \\
\text { group }\end{array}$ \\
\hline $2 \mathrm{~h}$ & $28.33 \pm 1.53$ & $43.67 \pm 5.72^{\mathrm{a}}$ & $38.0 \pm 7.54$ & $38.33 \pm 2.81$ & $39.17 \pm 7.11$ \\
$6 \mathrm{~h}$ & $28.33 \pm 1.53$ & $48.67 \pm 5.32^{\mathrm{a}}$ & $36.33 \pm 4.97^{\mathrm{b}}$ & $35.0 \pm 7.40^{\mathrm{b}}$ & $35.17 \pm 9.07^{\mathrm{b}}$ \\
$24 \mathrm{~h}$ & $23.5 \pm 1.87$ & $55.33 \pm 12.79^{\mathrm{a}}$ & $34.5 \pm 6.12^{\mathrm{b}}$ & $37.5 \pm 12.01^{\mathrm{b}}$ & $31.33 \pm 11.29^{\mathrm{b}}$ \\
\hline
\end{tabular}

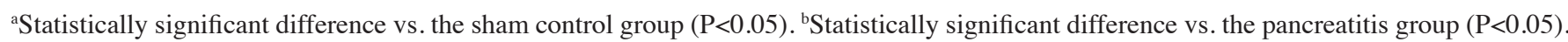
Metastab, methylprednisolone; IL, interleukin; TNF, tumor necrosis factor; CTX, cyclophosphamide; MTX, methotrexate.

Table II. Serum changes in anti-inflammatory cytokines at $24 \mathrm{~h}$.

\begin{tabular}{|c|c|c|c|c|c|}
\hline $\begin{array}{l}\text { Cytokines } \\
(\mathrm{pg} / \mathrm{ml})\end{array}$ & $\begin{array}{l}\text { Sham control } \\
\text { group }\end{array}$ & $\begin{array}{c}\text { Pancreatitis } \\
\text { group }\end{array}$ & $\begin{array}{c}\text { Metastab } \\
\text { group }\end{array}$ & $\begin{array}{l}\text { CTX } \\
\text { group }\end{array}$ & $\begin{array}{l}\text { MTX } \\
\text { group }\end{array}$ \\
\hline IL-10 & $32.05 \pm 14.87$ & $68.13 \pm 19.9^{\mathrm{a}}$ & $32.13 \pm 6.51^{b}$ & $39.47 \pm 15.69^{b}$ & $33.65 \pm 13.67^{b}$ \\
\hline TGF- $\beta$ & $6.4 \pm 13.2$ & $103.77 \pm 28.95^{\mathrm{a}}$ & $63.77 \pm 15.91^{\mathrm{b}}$ & $88.27 \pm 27.38$ & $61.88 \pm 11.01^{\mathrm{b}}$ \\
\hline
\end{tabular}

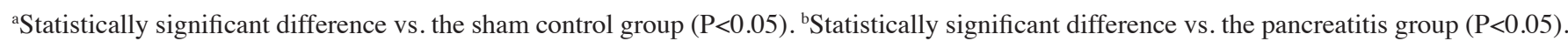
Metastab, methylprednisolone; CTX, cyclophosphamide; MTX, methotrexate; IL, interleukin; TGF, transforming growth factor.

$(\mathrm{P}<0.05)$, albeit higher compared to those in group 1 with sham intervention (Table II).

Amylase and $P W W$. After successfully generating an acute pancreatitis model in group 2, distinct pancreatic tissue congestion and edema were observed within $2 \mathrm{~h}$, along with turbid ascites. Pancreatic swelling peaked within $6 \mathrm{~h}$, with the average PWW reaching $1.86 \mathrm{~g}$. Within $24 \mathrm{~h}$, the level of swelling was slightly reduced and the average PWW was $1.30 \mathrm{~g}$, which was significantly higher compared to that in group $1(\mathrm{P}<0.05)$. Partial saponification spots were observed on the peritoneum in some animals. In group 2, the serum level of pancreatic amylase was also significantly increased compared to that in group 1 $(\mathrm{P}<0.05)$, verifying that acute pancreatitis was successfully induced. After immunosuppressant treatment, the indicators of acute pancreatitis severity varied among groups 3, 4 and 5. In group 3, which was treated with methylprednisolone, the decline in pancreatic amylase level was not significant compared to group 2 ( $\mathrm{P}>0.05)$; however, the PWW was significantly reduced $(\mathrm{P}<0.05$ vs. group 2$)$. Following CTX treatment in group 4 , the serum levels of pancreatic amylase and PWW were significantly decreased compared to group $2(\mathrm{P}<0.05)$. In group 5, which was treated with MTX, the serum pancreatic amylase levels were significantly decreased $(\mathrm{P}<0.05)$. However, the decrease in PWW was not statistically significant (Table III).

WBC count. In group 2, rats with acute pancreatitis exhibited slightly elevated WBC counts. After immunosuppressant 
Table III. Effect of immunosuppressant agents on acute pancreatitis at $24 \mathrm{~h}$.

\begin{tabular}{lccccc}
\hline Variable & $\begin{array}{c}\text { Sham control } \\
\text { group }\end{array}$ & $\begin{array}{c}\text { Pancreatitis } \\
\text { group }\end{array}$ & $\begin{array}{c}\text { Metastab } \\
\text { group }\end{array}$ & $\begin{array}{c}\text { CTX } \\
\text { group }\end{array}$ & $\begin{array}{c}\text { MTX } \\
\text { group }\end{array}$ \\
\hline Amylase (U/l) & $374.2 \pm 92.84$ & $1,817.25 \pm 459.35^{\mathrm{a}}$ & $1,382.17 \pm 1,029.33$ & $520.67 \pm 261.4^{\mathrm{b}}$ & $766.33 \pm 373.37^{\mathrm{b}}$ \\
PWW $(\mathrm{g})$ & $0.50 \pm 0.09$ & $1.30 \pm 0.13^{\mathrm{a}}$ & $1.03 \pm 0.19^{\mathrm{b}}$ & $1.25 \pm 0.21$ & $0.85 \pm 0.22^{\mathrm{b}}$ \\
WBC $\left(1 \times 10^{9} / \mathrm{l}\right)$ & $6.69 \pm 2.59$ & $6.93 \pm 0.67$ & $6.68 \pm 2.10$ & $4.88 \pm 1.47$ & $5.45 \pm 1.72$ \\
Neutrophil $(\%)$ & $35 \pm 9$ & $62 \pm 14$ & $50 \pm 21$ & $59 \pm 21$ & $56 \pm 16$ \\
\hline
\end{tabular}

${ }^{\text {aS }}$ Statistically significant difference vs. the sham control group $(\mathrm{P}<0.05)$. ${ }^{\mathrm{b}}$ Statistically significant difference vs. the pancreatitis group $(\mathrm{P}<0.05)$. Metastab, methylprednisolone; CTX, cyclophosphamide; MTX, methotrexate; PWW, pancreatic wet weight; WBC, white blood cell.

treatment, the WBC count in groups 3, 4 and 5 was not found to be significantly decreased at $24 \mathrm{~h}$ after treatment (Table III).

\section{Discussion}

Abnormal inflammatory responses play an important role in acute pancreatitis and the evolution of the disease process. During the early phase, dysregulation of the immunological reaction in SIRS dominates the pathological process and leads to circulatory disturbances and multiple organ dysfunction; during the late phase of the disease, the compensatory anti-inflammatory response syndrome (CARS) is highly likely to evoke infections $(2,33,34)$. Multiple organ dysfunction and infection are the leading causes of mortality in severe acute pancreatitis (35-38). Therefore, ameliorating the immune reaction of acute pancreatitis has been the focus of investigation over the last few years. Despite progress in elucidating the pathophysiology of SIRS and MODS over the last two decades, immune modulation therapies have failed to meet clinical requirements. Several investigators attempted to target the SIRS process by addressing the abnormal increases in the levels of inflammatory factors and cohesion molecules. To date, several corresponding antagonists, such as anti-endotoxin antibody (39-41), anti-TNF- $\alpha$ monoclonal antibody (42-44), anti-IL-1 $\beta$ soluble receptor (45-47), platelet-activating factor antagonists (48-50), anti-IL-8 monoclonal antibody (51) and anti-polymorphonuclear leukocytes-endothelial cell adhesion monoclonal antibody (recombinant humanized monoclonal antibody against CD18; rhuMAb CD18) $(52,53)$ have been designed. A series of biological agents, although remarkably effective in sequence and animal experiments, were not therapeutically effective in clinical trials. This may be partially explained by the differences among species, as well as the fact that all the cytokines and inflammatory mediators involved in the immune response are part of a multi-level, network-like framework. The entire cascade of cytokines and inflammatory mediators intermingled with numerous positive, negative and bypass feedback circles, preclude the possibility of halting the entire inflammatory response by blocking a single cytokine or inflammatory mediator. Furthermore, during the course of SIRS and MODS, a potent inflammatory response is often accompanied by an equally rampant anti-inflammatory response. Unilateral inhibition of inflammatory cytokines with a subsequent increase in anti-inflammatory signaling may increase the risk of infection $(54,55)$. During the investigation of immune regulation therapies for the treatment of SIRS and acute pancreatitis, a number of novel anti-inflammatory agents were identified, including APC $(56,57), \mathrm{Cl}$ esterase inhibitor $(58,59)$ and IL-10 $(60,61)$. These new anti-inflammatory agents exhibit promising therapeutic effects and, in contrast to the above-mentioned antagonists against single-cell factors or inflammatory mediators, they mainly inhibit a variety of cytokines and also play a role in the regulation of coagulation function and microcirculation. IL-10 as a treatment of acute pancreatitis has received wide recognition, although its use remains controversial. The majority of investigators reported that IL-10 achieved positive therapeutic effects in acute pancreatitis in animal experiments and clinical trials, most likely due to its ability to downregulate the overall inflammatory cytokine levels. The optimal medication for acute pancreatitis should fully downregulate SIRS and CARS reactions in order to revert the immune system to a reasonably balanced and healthy state at multiple levels.

The mechanisms underlying the regulatory role of immunosuppressants, particularly MTX and CTX, require further investigation. It was previously indicated that glucocorticoids block IL-1b and IL-6 synthesis in acute pancreatitis by interfering with gene transcription (61). In autoimmune diseases, such as IBD and RA, MTX was shown to inhibit T-cell hyperplasia and the activity of $F c \gamma$ receptors on monocytes to suppress pro-inflammatory cytokines, such as TNF- $\alpha$, IL-1 and IL-6 $(62,63)$. Similar mechanisms may be involved in the present study. In experimental animals with acute pancreatitis, the serum levels of pro-inflammatory cytokines (e.g., IL-1 $\alpha$, TNF- $\beta$ and IL-6) and anti-inflammatory cytokines (e.g., IL-10 and TGF- $\beta$ ) were all increased successively, providing further evidence that SIRS and CARS co-exist during the course of acute pancreatitis. After immunosuppressant administration, pro- and anti-inflammatory cytokine levels were significantly decreased to variable degrees, as were the amylase level and PWW, which are considered to be indicative of the severity of acute pancreatitis. The total leukocyte numbers exhibited a tendency to decrease in the MTX and CTX groups, although their decrease did not reach statistical significance. However, under the condition of a low level of pro-inflammatory cytokines, there is a possibility of lethal infection due to excessive anti-inflammatory cytokine production (24). In this study, immunosuppressants were able to downregulate pro- as well as anti-inflammatory cytokine levels close to normal levels. The regulation of anti-inflammatory cytokines may prevent the 
excessive inhibition of pro-inflammatory cytokines. Of note, the levels of cytokines in the groups treated with immunosuppressants were higher compared to those in the control group, which suggests that the immunosuppressants attenuated, but not completely blocked the inflammatory reaction. There are several differences between animal experiments and the clinical setting; thus, we do recommend immunosuppressants as a therapy for acute pancreatitis. However, this study may provide new evidence for the therapeutic utility of this type of treatment for acute pancreatitis and SIRS. Further experiments, including survival analyses and biopsy investigations, are required to verify our observations.

\section{References}

1. Baue AE, Durham R and Faist E: Systemic inflammatory response syndrome (SIRS), multiple organ dysfunction syndrome (MODS), multiple organ failure (MOF): are we winning the battle? Shock 10: 79-89, 1998.

2. Murata A, Kikuchi M, Mishima S, et al: Cytokine imbalance in critically ill patients: SIRS and CARS. Nihon Geka Gakkai Zasshi 100: 414-418, 1999 (In Japanese).

3. Mayer J, Rau B, Gansauge F and Beger HG: Inflammatory mediators in human acute pancreatitis: clinical and pathophysiological implications. Gut 47: 546-552, 2000.

4. Brady M, Christmas S, Sutton R, Neoptolemos J and Slavin J: Cytokines and acute pancreatitis. Baillieres Best Pract Res Clin Gastroenterol 13: 265-289, 1999.

5. Hirota M, Nozawa F, Okabe A, et al: Relationship between plasma cytokine concentration and multiple organ failure in patients with acute pancreatitis. Pancreas 21: 141-146, 2000.

6. Goris RJ: MODS/SIRS: result of an overwhelming inflammatory response? World J Surg 20: 418-421, 1996.

7. de Beaux AC, Goldie AS, Ross JA, Carter DC and Fearon KC: Serum concentrations of inflammatory mediators related to organ failure in patients with acute pancreatitis. Br J Surg 83: 349-353, 1996.

8. Brivet FG, Emilie D and Galanaud P: Pro- and anti-inflammatory cytokines during acute severe pancreatitis: an early and sustained response, although unpredictable of death. Parisian Study Group on Acute Pancreatitis. Crit Care Med 27: 749-755, 1999.

9. Bamias G and Cominelli F: Immunopathogenesis of inflammatory bowel disease: current concepts. Curr Opin Gastroenterol 23 : 365-369, 2007.

10. Brennan F and Beech J: Update on cytokines in rheumatoid arthritis. Curr Opin Rheumatol 19: 296-301, 2007.

11. Kyttaris VC, Juang YT and Tsokos GC: Immune cells and cytokines in systemic lupus erythematosus: an update. Curr Opin Rheumatol 17: 518-522, 2005.

12. Suarez A, Lopez P, Mozo L and Gutierrez C: Differential effect of IL10 and TNF $\alpha$ genotypes on determining susceptibility to discoid and systemic lupus erythematosus. Ann Rheum Dis 64: $1605-1610,2005$

13. Hanauer SB: Inflammatory bowel disease: epidemiology, pathogenesis, and therapeutic opportunities. Inflamm Bowel Dis 12 (Suppl 1): S3-S9, 2006.

14. Podolsky DK: Inflammatory bowel disease. N Engl J Med 347: 417-429, 2002.

15. Scott DL: Early rheumatoid arthritis. Br Med Bull 81-82: 97-114, 2007.

16. Meesters EW, Hansen H, Spronk HM, et al: The inflammation and coagulation cross-talk in patients with systemic lupus erythematosus. Blood Coagul Fibrinolysis 18: 21-28, 2007.

17. Kim HR, Cho ML, Kim KW, et al: Up-regulation of IL-23p19 expression in rheumatoid arthritis synovial fibroblasts by IL-17 through PI3-kinase-, NF-kappaB- and p38 MAPK-dependent signalling pathways. Rheumatology (Oxford) 46: 57-64, 2007.

18. Liu FL, Chen CH, Chu SJ, et al: Interleukin (IL)-23 p19 expression induced by IL-1beta in human fibroblast-like synoviocytes with rheumatoid arthritis via active nuclear factor-kappaB and AP-1 dependent pathway. Rheumatology (Oxford) 46: 1266-1273, 2007

19. Metsios GS, Stavropoulos-Kalinoglou A, Douglas KM, et al: Blockade of tumour necrosis factor-alpha in rheumatoid arthritis: effects on components of rheumatoid cachexia. Rheumatology (Oxford) 46: 1824-1827, 2007.
20. Nixon R, Bansback N and Brennan A: The efficacy of inhibiting tumour necrosis factor alpha and interleukin 1 in patients with rheumatoid arthritis: a meta-analysis and adjusted indirect comparisons. Rheumatology (Oxford) 46: 1140-1147, 2007.

21. van der Kooij SM, Allaart CF, Dijkmans BA and Breedveld FC: Innovative treatment strategies for patients with rheumatoid arthritis. Curr Opin Rheumatol 20: 287-294, 2008.

22. Wiesendanger M, Stanevsky A, Kovsky S and Diamond B: Novel therapeutics for systemic lupus erythematosus. Curr Opin Rheumatol 18: 227-235, 2006.

23. Faioni EM, Ferrero S, Fontana G, et al: Expression of endothelial protein $\mathrm{C}$ receptor and thrombomodulin in the intestinal tissue of patients with inflammatory bowel disease. Crit Care Med 32 (Suppl 5): S266-S270, 2004.

24. Nojima J, Kuratsune H, Suehisa E, et al: Acquired activated protein $\mathrm{C}$ resistance is associated with the co-existence of anti-prothrombin antibodies and lupus anticoagulant activity in patients with systemic lupus erythematosus. Br J Haematol 118: 577-583, 2002.

25. Johnson RM, Barone RM, Newson BL, Das Gupta TK and Nyhus LM: Treatment of experimental acute pancreatitis with 5-flourouracil (5-FU). Am J Surg 125: 211-222, 1973.

26. Saario IA: 5-Fluorouracil in the treatment of acute pancreatitis. Am J Surg 145: 349-352, 1983.

27. Muller CA, Vogeser M, Belyaev O, et al: Role of endogenous glucocorticoid metabolism in human acute pancreatitis. Crit Care Med 34: 1060-1066, 2006.

28. Rakonczay Z Jr, Duda E, Kaszaki J, et al: The anti-inflammatory effect of methylprednisolone occurs down-stream of nuclear factor-kappaB DNA binding in acute pancreatitis. Eur J Pharmacol 464: 217-227, 2003.

29. Luo S, Wang R, Jiang W, Lin X, Qiu P and Yan G: A novel recombinant snake venom metalloproteinase from Agkistrodon acutus protects against taurocholate-induced severe acute pancreatitis in rats. Biochimie 92: 1354-1361, 2010.

30. Lederer JA and Czuprynski CJ: Production and purification of bovine monocyte-derived interleukin 1. Vet Immunol Immunopathol 23: 201-211, 1989.

31. Kimura H, Ishibashi T, Shikama Y, Okano A, Akiyama Y, Uchida $\mathrm{T}$ and Maruyama Y: Interleukin-1 beta (IL-1 beta) induces thrombocytosis in mice: possible implication of IL-6. Blood 76: 2493-2500, 1990.

32. Heo DS, Park JG, Hata K, Day R, Herberman RB and Whiteside TL: Evaluation of tetrazolium-based semiautomatic colorimetric assay for measurement of human antitumor cytotoxicity. Cancer Res 50: 3681-3690.

33. Hirota M, Nozawa F, Okabe A, Shibata M, Kuwata K and Ogawa M: SIRS and CARS: discussion based on the pathologic condition of acute pancreatitis. Jpn J Clin Pathol 48: 527-532, 2000 (In Japanese).

34. Ono S, Ichikura T and Mochizuki $\mathrm{H}$ : The pathogenesis of the systemic inflammatory response syndrome and compensatory antiinflammatory response syndrome following surgical stress. Nihon Geka Gakkai Zasshi 104: 499-505, 2003 (In Japanese).

35. Ammori BJ, Leeder PC, King RF, et al: Early increase in intestinal permeability in patients with severe acute pancreatitis: correlation with endotoxemia, organ failure, and mortality. J Gastrointest Surg 3: 252-262, 1999.

36. Schmid SW, Uhl W, Friess H, Malfertheiner P and Buchler MW: The role of infection in acute pancreatitis. Gut 45: 311-316, 1999.

37. Pitchumoni CS, Patel NM and Shah P: Factors influencing mortality in acute pancreatitis: can we alter them? J Clin Gastroenterol 39: 798-814, 2005.

38. Bumbasirevic V, Radenkovic D, Jankovic Z, et al: Severe acute pancreatitis: overall and early versus late mortality in intensive care units. Pancreas 38: 122-125, 2009.

39. Ziegler EJ, Fisher CJ Jr, Sprung CL, et al: Treatment of gram-negative bacteremia and septic shock with HA-1A human monoclonal antibody against endotoxin. A randomized, double-blind, placebo-controlled trial. The HA-1A Sepsis Study Group. N Engl J Med 324: 429-436, 1991.

40. Stack AM, Saladino RA, Siber GR, et al: A comparison of bacteri cidal/permeability-increasing protein variant versus recombinant endotoxin-neutralizing protein for the treatment of Escherichia coli sepsis in rats. Crit Care Med 25: 101-105, 1997.

41. Jiang J, Zhu P, Wang Z, et al: Protective effect of bactericidal/p ermeability-increasing protein in mice with E. coli sepsis. Chin J Traumatol 1: 21-24, 1998 .

42. Fisher CJ Jr, Agosti JM, Opal SM, et al: Treatment of septic shock with the tumor necrosis factor receptor: $\mathrm{Fc}$ fusion protein. The Soluble TNF Receptor Sepsis Study Group. N Engl J Med 334: $1697-1702,1996$. 
43. Clark MA, Plank LD, Connolly AB, et al: Effect of a chimeric antibody to tumor necrosis factor-alpha on cytokine and physiologic responses in patients with severe sepsis - a randomized, clinical trial. Crit Care Med 26: 1650-1659, 1998.

44. Reinhart K, Wiegand-Lohnert C, Grimminger F, et al: Assessment of the safety and efficacy of the monoclonal anti-tumor necrosis factor antibody-fragment, MAK 195F, in patients with sepsis and septic shock: a multicenter, randomized, placebo-controlled, dose-ranging study. Crit Care Med 24: 733-742, 1996.

45. Fisher CJ Jr,Slotman GJ, Opal SM, et al: Initial evaluation of human recombinant interleukin-1 receptor antagonist in the treatment of sepsis syndrome: a randomized, open-label, placebo-controlled multicenter trial. Crit Care Med 22: 12-21, 1994.

46. Fink G, Yang J, Carter G and Norman J: Acute pancreatitis-induced enzyme release and necrosis are attenuated by IL-1 antagonism through an indirect mechanism. J Surg Res 67: 94-97, 1997.

47. Opal SM, Fisher CJ Jr, Dhainaut JF, et al: Confirmatory interleukin-1 receptor antagonist trial in severe sepsis: a phase III, randomized, double-blind, placebo-controlled, multicenter trial. The Interleukin-1 Receptor Antagonist Sepsis Investigator Group. Crit Care Med 25: 1115-1124, 1997.

48. Dhainaut JF, Tenaillon A, Hemmer M, et al: Confirmatory platelet-activating factor receptor antagonist trial in patients with severe gram-negative bacterial sepsis: a phase III, randomized, double-blind, placebo-controlled, multicenter trial. BN 52021 Sepsis Investigator Group. Crit Care Med 26: 1963-1971, 1998.

49. Zimmerman GA, McIntyre TM, Prescott SM and Stafforini DM: The platelet-activating factor signaling system and its regulators in syndromes of inflammation and thrombosis. Crit Care Med 30 (Suppl 5): S294-S301, 2002.

50. Poeze M, Froon AH, Ramsay G, Buurman WA and Greve JW: Decreased organ failure in patients with severe SIRS and septic shock treated with the platelet-activating factor antagonist TCV-309: a prospective, multicenter, double-blind, randomized phase II trial. TCV-309 Septic Shock Study Group. Shock 14: 421-428, 2000

51. Osman MO, Kristensen JU, Jacobsen NO, et al: A monoclonal anti-interleukin 8 antibody (WS-4) inhibits cytokine response and acute lung injury in experimental severe acute necrotising pancreatitis in rabbits. Gut 43: 232-239, 1998.
52. Rhee P, Morris J, Durham R, et al: Recombinant humanized monoclonal antibody against CD18 (rhuMAb CD18) in traumatic hemorrhagic shock: results of a phase II clinical trial. Traumatic Shock Group. J Trauma 49: 611-620, 2000.

53. Allison DE, Gourlay SG, Koren E, Miller RM and Fox JA: Pharmacokinetics of rhuMAb CD18, a recombinant humanised monoclonal antibody fragment to CD18, in normal healthy human volunteers. BioDrugs 16: 63-70, 2002.

54. Iwagaki H, Hizuta A, Uomoto M, et al: Clinical value of cytokine antagonists in infectious complications. Res Commun Mol Pathol Pharmacol 96: 25-34, 1997.

55. Remick DG: Cytokine therapeutics for the treatment of sepsis: why has nothing worked? Curr Pharm Des 9: 75-82, 2003.

56. Yan SB, Helterbrand JD, Hartman DL, Wright TJ and Bernard GR: Low levels of protein $\mathrm{C}$ are associated with poor outcome in severe sepsis. Chest 120: 915-922, 2001.

57. Bernard GR, Vincent JL, Laterre PF, et al: Efficacy and safety of recombinant human activated protein $\mathrm{C}$ for severe sepsis. $\mathrm{N}$ Engl J Med 344: 699-709, 2001.

58. Jansen PM, Eisele B, de Jong IW, et al: Effect of C1 inhibitor on inflammatory and physiologic response patterns in primates suffering from lethal septic shock. J Immunol 160: 475-484, 1998.

59. Caliezi C, Zeerleder S, Redondo M, et al: C1-inhibitor in patients with severe sepsis and septic shock: beneficial effect on renal dysfunction. Crit Care Med 30: 1722-1728, 2002.

60. Oberholzer A, Oberholzer C, Efron PA, et al: Functional modification of dendritic cells with recombinant adenovirus encoding interleukin 10 for the treatment of sepsis. Shock 23: 507-515, 2005.

61. Rajan S, Vyas D, Clark AT, et al: Intestine-specific overexpression of IL-10 improves survival in polymicrobial sepsis. Shock 29: 483-489, 2008

62. Wijngaarden S, van Roon JA, van de Winkel JG, Bijlsma JW and Lafeber FP: Down-regulation of activating Fcgamma receptors on monocytes of patients with rheumatoid arthritis upon methotrexate treatment. Rheumatology (Oxford) 44: 729-734, 2005.

63. Soon SY, Ansari A, Yaneza M, Raoof S, Hirst J and Sanderson JD: Experience with the use of low-dose methotrexate for inflammatory bowel disease. Eur J Gastroenterol Hepatol 16: 921-926, 2004. 